\title{
A Suggested Proposal to Develop Distance Learning Programs in Border Schools in the Kingdom of Saudi Arabia
}

\author{
Noura H. Al Sorour ${ }^{1} \&$ Mohamed Osman M. El-hussein ${ }^{2}$ \\ ${ }^{1}$ Teacher Forensic Science and Honest Sources of Learning in the Fifth Primary School for Girls, Kingdom of \\ Saudi Arabia \\ ${ }^{2}$ Assistant Professor Department of Instruction Media and Technology, Arab East College for Graduate Studies, \\ Kingdom of Saudi Arabia \\ Correspondence: Noura H. Al Sorour, the Fifth Primary School for Girls, Najran, Kingdom of Saudi Arabia. Tel: \\ 966-505-689-830. E-mail: balssaftly@gmail.com
}

Received: November 10, 2021

Accepted: December 13, 2021

Online Published: January 10, 2022

doi:10.5539/hes.v12n1p60

URL: https://doi.org/10.5539/hes.v12n1p60

\begin{abstract}
The aim of this research is to find a proposed vision for developing distance education programs in border schools in the Kingdom of Saudi Arabia, and to explore the reality of the proposed educational programs for developing distance education programs. In order to achieve the research objectives, the descriptive and analytical approach was used for its suitability for this research, as the questionnaire was used as a research tool. The research sample consisted of (150) female teachers from border schools. The results of the research revealed that the reality of female teachers 'practice on distance learning programs in border schools in the Kingdom of Saudi Arabia is central. And that the use of technology is the most important requirement for developing distance education programs in border schools from the Kingdom of Saudi Arabia. The results also showed the achievement of leadership in diversifying and developing teaching and learning methods through the distance education system based on employing modern information and communication technology, equipping schools with all technological equipment, and supporting students with modern equipment and teachers with modern training to achieve the goals of distance education. In light of the results, the research paper presented a proposal for developing distance education programs in border schools in the Kingdom of Saudi Arabia.
\end{abstract}

Keywords: female teachers, distance education, technology

\section{Introduction}

E-learning has been implemented in various learning institutions, especially within their departments, and the scope of its use has also been expanded in some commercial and professional companies, to include employees and customers alike.

This age is characterized by rapid changes resulting from scientific and technological progress, especially as there are many researches that take on the responsibility of information and communication technology in education. Therefore, it became necessary for workers and researchers in the educational field to keep pace with the educational process of these changes and to choose a good application for effective practice, especially in distance education. Distance education may include other terms such as e-learning, online education, computer-based training, technology-enhanced learning and others. E-learning has been implemented in various learning institutions, especially within their departments, and the scope of its use has also been expanded in some commercial and professional companies, to include employees and customers alike. The importance of e-learning has led to the need to assess the mental and physical preparation of users before using the distance education environment; therefore, users must be provided who are able to use the technology of the e-learning environment in the best technical way possible. Interest in distance education has increased in recent years with all its means. This is to open new technological horizons for learners, teachers, experts and researchers - that were not available before - and to prepare it as a promising solution to the needs of future students. And since the skills required in e-learning are completely different from the normal teaching skills, such as communication skills, internet services, organizing electronic classes, and others. It is necessary to ensure the readiness of this type of learning in order to achieve the objectives behind it .... Based on the above, this research paper will analyze the factors of readiness of educational institutions in border schools for e-learning (resources, skills, and 
educational attitudes), and their relevance to technology, teachers and self-development. Alghamdi's study (2016, p27) indicated that distance education is an interest in Saudi education, but that there are some physical, personal and administrative restrictions that affect distance learning in the Kingdom of Saudi Arabia.

\section{The Research Problem}

As the Internet and other computer technology continue to develop rapidly, e-learning has become an emerging learning method that can provide adaptive learning services, thereby significantly improving learning effectiveness (Chu, 2020). Aparicio et al claim that e-learning concept was not the first term to be used in conceptualizing the use of computerized systems to enable or facilitate the learning process. They identified 23 concepts that belong to the use of computers for learning purposes. e.g., online learning, virtual learning, distance education, m-learning, MOOC, learning management systems (Berrocoso et al., 2020). Computer technologies allow exchanging information meaningfully at any distance within the framework of the student-teacher system. Moreover, this learning mode has many advantages than the traditional mode, as it provides the students with the ability to learn at their own pace and in their own space (Leontyeva, 2018). Against the backdrop of the COVID-19 outbreak various policy initiatives are being launched by governments and tertiary institutions across the world to continue teaching activities so as to contain the virus. However, there is ambiguity and disagreement about what to teach, how to teach, the workload of teachers and students, the teaching environment, and the implications for education equity (Ali, 2020). The Ministry of Education in the Kingdom of Saudi Arabia seeks to achieve the enhancement of the capabilities of individuals and the connection with others, the products of knowledge and information flow, therefore it has directed towards intensifying efforts to popularize the idea of e-learning, which is one of the most recent methods in the world of training and education (Durm, 2011). Therefore, the research problem emerges from the current situation of the educational process. Online learning in border schools in the Kingdom of Saudi Arabia that have been subjected to academic suspension for consecutive periods; Hence, the Ministry of Education in the Kingdom resorted to electronically adopting educational alternatives remotely for male and female students in southern border schools, represented by four alternatives: educational bags, virtual classes, interactive courses, and educational channels, as the Minister of Education explained at the time that these alternatives are only a facilitation for male and female students To obtain education by transferring it or registering it as a visitor in any of the Saudi schools, and it can also be registered as a student affiliated with the home system, and these alternatives aim to facilitate education by choosing several new electronic methods and this is called e-learning (Haful, 2015).

The Ministry of Education developed a "twinning" plan between schools at the southern border in order to secure a safe environment for male and female students in schools. This plan includes providing the option of e-learning as one of the most important educational alternatives in providing education and presenting it to all students, in addition to the educational lessons channels, and the Aali satellite channel and making use of the distance education platforms "Jusoor" (Al-Thumairi, 2015). The restrictions that were imposed on movement in southern border schools, the increase in the dropout rate, and the inability of students and teachers to access schools in conflict areas, necessitated the Ministry of Education to create an alternative and supportive educational system that relies on distance education, by receiving education at home by accreditation On e-learning or in temporary alternative classes (Al-Kordali, 2015). Therefore, this research will focus on developing a proposed vision for developing distance education programs in border schools in the Kingdom of Saudi Arabia.

\section{Research Objectives}

- Monitor the reality of educational programs to develop distance education programs in border schools in the Kingdom of Saudi Arabia.

- Determining requirements for developing distance education programs in border schools in the Kingdom of Saudi Arabia.

- Identifying obstacles to developing distance education programs in border schools in the Kingdom of Saudi Arabia.

- Building a proposal for the development of distance education programs in the border schools of the Kingdom of Saudi Arabia.

\section{The Research Importance}

The importance of the research lies in the following:

- A new addition to enhance the development of the educational process, especially in border schools in Najran, in the Kingdom of Saudi Arabia. 
- Emphasizing the importance of having a proposed vision for e-learning to assist decision-makers in reducing obstacles to e-learning.

- Emphasizing the importance of having a proposed concept for e-learning to help in selecting teachers and preparing them for the educational process based on e-learning.

- Emphasizing the importance of having a proposed concept for e-learning to help increase the awareness of students 'parents about the benefits of modern technology in education, especially in following up and monitoring their students' children through e-learning, and enhancing communication with student teachers.

- Emphasizing the importance of having a proposed vision for e-learning to demonstrate the importance of using modern technology in education for students in border schools in Najran, to make it more effective.

- Emphasizing the importance of having a proposed concept for e-learning to help demonstrate the importance of using e-learning for teachers, especially in the process of evaluation and communication with students effectively and quickly.

\section{Theoretical Framework}

\subsection{The Distance Education Concept}

The delivery of education to students, who are not physically present, with the help of satellite, video, audio, graphic, computer and multimedia technologies is defined as distance education (Cubukcu \& Akturk, 2020).

Guan et al. (2015) pointed out that new developments in information technology and communication systems have led to the issuance of new literature, and different terms are used in the interpretation of online learning. Commonly used terms include (e-learning, online learning, virtual learning, computer-aided learning, web-based learning, and distance learning, etc.).

Teaching remotely is not the same as teaching in a classroom and requires substantive adjustments for teachers to direct, engage and support children with home learning (Alam \& Tiwari, 2020).

Monika (2013) noted that the evolving definition of e-learning describes e-learning as educational content or learning experiences that are provided or enabled by Internet technology to enhance an individual's knowledge and performance. As Salyers et al. (2014) showed that e-learning, since its inception in the 1990s, has found its way into the public, private, and institutional sectors, and educational circles ranging from the K-12 sector to adult education. Moreover, its growth shows no signs. On the slowdown: In 2011, the global e-learning market was \$ 35.6 billion, and it is estimated that there will be additional growth of approximately $7.6 \%$, with revenues increasing to $\$ 51.5$ billion over the next year. Five years. Recently, mobile learning and open online courses (MOOCs) have increased public awareness of e-learning. In light of this phenomenon, it is more important than ever to use best practices to ensure high-quality learning experiences.

The advanced means of communication have created new educational patterns to serve the educational system in a modern and modern way and address the problems of time and space, in addition to economic, political and social problems, and the most important of these patterns is distance education. According to (Al-Dabbasi, 2002), he believes that the power of distance education appears by looking at it from three sides:

- From the learner's perspective: Distance education works to achieve flexibility and freedom for the learner, meaning that the learner is freed from the restrictions of time and place, and it gives him more educational opportunities.

- From the employers' perspective: Distance education provides opportunities to train workers and develop their technical and professional skills, thus increasing production, quality and reducing costs.

- From the state's perspective: Distance education works to democratize education, by increasing the number of learners and connecting education and training systems to individuals who only have certain opportunities from traditional education and training.

Distance education is affected by the contemporary technical revolution, and distance education seeks to develop science and knowledge and its applications in various fields through the use of advanced technology means, and distance education is the tool through which it looks to all sectors operating in society in order to advance all segments of society. Therefore, distance education must be known more broadly.

The main elements of a definition of distance education are (Saykili, 2018):

- the separation of teacher and learner which distinguishes it from face-to-face $(\mathrm{F} 2 \mathrm{~F})$ lecturing.

- the influence of an educational organization which distinguishes it from private study. 
- the use of technical media, usually print, to unite teacher and learner and carry the educational content of the course.

- the provision of two-way communication so that the student may benefit from or even initiate dialogue.

- the possibility of occasional meetings for both didactic and socialization purposes.

- the participation in an industrialized form of education.

\subsection{Advantages and Disadvantages of Distance Education}

Distance education has a number of advantages, the most important of which are (Ministry of Higher Education, 2006):

- Increasing cooperative and participatory learning opportunities among learners by discussing ideas, facts and concepts using brainstorming and assigning tasks.

- Providing all registered and unregistered learners in educational institutions with educational tools and materials, which results in universal access to ample educational opportunities.

- The learner's access to educational resources, references, and materials by receiving knowledge from a variety of widely spaced, well-designed educational destinations available in the learner's location.

- Its development of self-learning skills and the development of scientific research among learners. It also increases the availability of multiple educational resources that support critical thinking.

- Educational interaction between the teacher and the learner, which is supported by direct and indirect transmission through electronic technical means such as radio, satellites, video, computer programs, multimedia systems, e-mail or special programs that are broadcast from educational institutions via the Internet, which work side by side with textbooks.

- Non-compliance with place and time, as the educational process can occur at any time and in any place, through educational means.

- Low cost of distance learning, as traditional education requires a large cost, and the time, effort and educational curricula can also be reduced.

- Exchange of experiences, as distance education provides opportunities for communication between students of different cultures, customs and concepts around the world, which provides an opportunity to exchange various experiences.

- The learner feels safe and secure, as he does not always need direct face-to-face interaction with the teacher, but this is done through technology such as television, phone and computer.

There are some drawbacks to distance education, which reduce the chances of obtaining the results we hope for from it, and psychological and social factors are among the most important of those negatives, in terms of (Amer \& Al-Mousawi, 2010):

- Reducing scientific interaction in terms of visiting remote libraries or learning resource centers.

- Weak social interaction between the teacher and his students and between the students and each other.

- The learner's misuse of technology, especially attempts to cheat, plagiarism, and what is related to intellectual rights.

- Lack of complete control over the tests that are done with the distance learning system.

5.3 Factors and Obstacles to the Success of Distance Education

Al-Makhdoub (2008) identified the factors that affect the success of distance education as follows:

- Flexibility in using the system.

- Interactive between teacher and student.

- Provide the elements of feedback in all directions (from teacher to student, between students and themselves).

- Providing appropriate teaching methods that support the teacher and make him assume responsibility.

- Provision of equipment and devices.

- Adequate training for teachers and students.

- Providing the necessary financial resources. 
Among the most prominent obstacles facing the application of distance education are the following (Al-Awada, 2012:

- Poor infrastructure for distance education, including means of communication and permanent maintenance.

- The lack of human cadres of teachers trained for this type of education.

- Perception of distance education as less adequate than traditional education.

- The learner's need for the self-desire to learn.

- The distance education systems are not clear enough.

\subsection{Key Elements of Distance Education}

While DE can be implemented through various technologies and approaches, the learner must be at the centre of planning and implementation. Key considerations for the effective design and delivery of a DE programme are (Kanwar, 2020):

A. Learning resources: Content is designed to support self-learning and made accessible to students using a variety of media and technology, including print, radio, television, computers, mobiles and the Internet. When there are clear objectives and support to achieve specific learning outcomes, effective teaching and learning can happen without students and teachers being in the same place at the same time.

B. Pedagogy: Teaching and learning is based on sound pedagogical principles of guided-didactic conversation, and appropriate use of two-way communication tools and technologies that help support dialogue and communication. Interaction between students and other students, students and teachers and students and content results in deeper understanding and is an integral part of DE. In order to benefit maximally from DE opportunities, students need to be guided to develop self-directed learning skills.

C. Learner support: Providing psychological and emotional support to learners at a distance alongside continuous academic interaction are keys to student success. Caring human support at a distance facilitates self-directed learning, reduces student isolation, and creates an environment for student engagements in learning.

D. Administration: DE is an industrialised form of teaching and learning characterised by division of labour. In order to implement effective teaching and learning at a distance, planning and organisation of the teaching and learning process from curriculum development to assessment of student learning needs to be managed by an efficient and accountable administration.

\section{Research Methodology}

In this research, the descriptive and analytical method, which is appropriate for such studies, was used. In this regard, Al-Assaf (2005) stated that this type of research aims to know some detailed facts about the reality of the studied phenomenon, which enables a comprehensive description and accurate diagnosis of that reality, which enables the issuance of evaluative judgments on a specific reality. It also aims to analyze specific experiences in order to benefit from them when deciding on similar matters in the future.

The research community consisted of all the female teachers in the "private and governmental" border schools located in Najran region in the Kingdom of Saudi Arabia, as their number reached (950) female teachers. The research sample was chosen in a cluster method that consisted of 150 female teachers.

To achieve the research objectives, work has been done on designing a questionnaire, in which the validity of the research tool was verified by verifying its apparent validity. By presenting it to researchers and academics who have an interest in the topic of research, and then making the necessary adjustments in light of the observations received from them. In order to extract validity indicators for all paragraphs of the study tool, it was applied to an exploratory sample of (20) individuals from outside the study sample and to calculate the correlation coefficients between each paragraph and the field to which it belongs and the whole tool. It was found that the correlation coefficients between each paragraph of the study tool and the axis to which it belongs The mechanism and the whole tool were high, and this indicates the existence of a strong correlation coefficient, which are acceptable correlation coefficients and a function at the level of significance $(\alpha=0.05)$ for the purposes of applying the study, and to ensure the instrument's accuracy and its ability to measure the factors to be revealed in the current research. Therefore, the test that measures the internal consistency of the paragraphs was used by relying on the Cronbach Alpha coefficient to ensure the degree of stability and coherence of the resolution. The whole tool (0.97). 


\section{Research Results}

\subsection{Results of the First Question}

What is the reality of the educational programs currently applied to develop distance education programs in the border schools of the Kingdom of Saudi Arabia?

To answer this question, arithmetic averages and standard deviations were extracted for all paragraphs of the reality of educational programs currently applied to develop distance education programs in border schools from the Kingdom of Saudi Arabia.

\subsubsection{The First Axis-Human Resources}

Regarding the degree of importance: The arithmetic averages for the paragraphs of the "human resources" axis ranged between (2.06-2.41) and the highest was for paragraph (8), which states, "The workers have the ability to define their own training needs." With an arithmetic average (2.41) and a high degree, followed by Paragraph No. (7) which states that "teachers have the ability to communicate effectively" ranked second with an arithmetic average (2.40) and with a high degree, and then Paragraph No. (6) which states that "working human resources have the ability to solve problems and make decisions" in the third rank With an arithmetic average (2.23) and a medium degree, and in the last rank Paragraph No. (2) which states that "the school has specialists to provide technical and technical support for distance education" with an arithmetic average (2.06) and a medium degree, and the arithmetic average for the entire "human resources" axis is (2.23) And a standard deviation (0.545), and most of the teachers 'opinions had a high degree of importance and a little was medium.

Relative to the degree of practice: The arithmetic averages of the human resources axis items ranged between (1.45-2.20) and the highest was for paragraph No. (7) which states that "teachers have the ability to communicate effectively" with an arithmetic average (2.20) and the degree of practice, followed by paragraphs No. $(4,8)$ that state "Workers have the ability to define their own training needs." "Employees (administrators teachers) accept the culture of distance education and its dependencies" in second place with an arithmetic average (2.11) and a medium degree, and then Paragraph No. (6) which states "Owning human resources The employee's ability to solve problems and make decisions, "ranked third with an arithmetic average (1.99) and a medium degree, and ranked last for Paragraph No. (5), which states" There is a sufficient number of external assistants and designers such as content design experts and programmers "with an arithmetic average (1.45) and a low grade.

\subsubsection{The Second Axis-Self-Development}

Regarding the degree of importance: The arithmetic averages of the degree of importance for the paragraphs of the "self-development" axis ranged between (2.13-2.42), the highest of which was for paragraph No. (8), which states that "workers have self-directed professional development and realize its importance in the field of distance education" with an arithmetic average (2.42) and a high degree, Followed by Paragraph No. (5) which states "the existence of a strategic plan to train workers on the required skills (now and in the future) for distance education," ranked second with an arithmetic average (2.36) and a high degree, and then Paragraph No. (1) that states "There is a structure Organizational, flexible, and adjustable (as needed) that fits the distance education system "in the third rank with an arithmetic average (2.35) and with a medium degree, and at the last rank Paragraph No. (6) which states:" The educational administration sends teachers on missions to advanced countries to train on modern skills for education Distance, with an arithmetic mean (2.13) and a medium degree, and the arithmetic average of the axis of "self-development" was (2.28). The opinions of the respondents on this axis were of moderate importance.

Relative to the degree of practice: The general arithmetic mean of the expressions of the axis of "self-development" was (1.80) and a standard deviation (0.575). The opinions of the respondents to the degree of practice varied between low and medium degrees. The arithmetic averages of the axis of "self-development" ranged between (1.56 - 2.03), the highest of which was for statement No. (8) ) "Workers have self-directed professional development and are aware of its importance in the field of distance education" with an arithmetic mean of (2.03) and a standard deviation (0.750) with a medium degree, followed by statement No. (4) "Administrative levels (upper - middle) believe in the value of training and professional development in Distance education "with an arithmetic mean of (1.99) and a standard deviation of (0.746) with a medium degree, and the statement No. (6) came last. The educational administration sends teachers on missions to developed countries to train in modern skills for distance education," with an arithmetic average of (1.56) And standard deviation (0.773). 


\subsection{Results of the Second Question}

What are the requirements for developing distance education programs in border schools from the Kingdom of Saudi Arabia?

To answer this question, arithmetic averages and standard deviations were extracted for all paragraphs of requirements for developing distance education programs in border schools from the Kingdom of Saudi Arabia.

\subsubsection{The Third Axis-Technology}

Regarding the degree of importance: The arithmetic averages of the items of the degree of importance for the "technology" axis ranged between (2.13 - 2.61) and the highest was for paragraph No. (10) which states "There is a website for the school to help students and faculty members" with an arithmetic average (2.61) and with a high degree, followed by paragraph No. (10) 3) which states that "workers have the desire to use technology in performing daily tasks" in second place with an arithmetic mean (2.60) and a standard deviation (0.655), and then paragraph No. (7) which states that "workers have the basic skills to deal with computers." In third place, with an arithmetic average (2.51) and a high degree, and in last rank, Paragraph No. (2) which states "providing access to fast internet services for workers inside and outside the school" with an arithmetic mean (2.13) and a standard deviation (0.820), and the general average for the technology axis is (2.47) The opinions of the respondents on this axis were of a high degree of importance.

Relative to the degree of practice: The arithmetic averages of the "technology" items ranged between (1.75-2.47), the most prominent of which was paragraph No. (6) which states that there is an electronic system for enrollment and registration of students with an arithmetic mean (2.47) and a standard deviation (0.757), then Paragraph No. 3 came ) With an arithmetic average (2.23) with a medium degree, which states that "workers have the desire to use technology in the performance of daily tasks," and the lowest arithmetic averages came to Paragraph No. (1) which states "The availability of a technological infrastructure in the school of equipment, systems and an electronic library." With a mean of (1.75), with a moderate degree. The general average of the paragraphs of the axis was (2.11) and a standard deviation (0.526). The opinions of the respondents in this axis varied between a weak and moderate degree of practice.

\subsubsection{The Fourth Axis-Innovations}

Regarding the degree of importance: The general arithmetic mean of the terms of the "innovations" axis was (2.29) and a standard deviation (0.596). The opinions of the respondents on this axis were of a high degree of importance. Whereas the arithmetic averages for the "innovations" axis ranged between (2.24 - 2.38), the highest was for the statement No. (1) "the administrative levels (upper - middle) support the changes required by the distance education system" with an arithmetic mean of (2.38) and a standard deviation (0.730). ) With a high degree, followed by the statement No. (7) "The school has an organizational culture that supports change and accepts the new" with an arithmetic mean of (2.35) and a standard deviation (0.751) with a medium degree, and No. (3) came in last place. School) partnership and cooperation agreements with communications and information technology companies, with an arithmetic mean of (2.24) and a standard deviation (0.817).

Relative to the degree of practice: The arithmetic averages of the sections of the practice score for the "innovations" axis ranged between (1.63 - 2.11) and the highest was for Paragraph No. (7) which states "The school has an organizational culture that supports change and accepts the new" with an arithmetic mean (2.11) and a medium degree, followed by paragraph No. (2) Which states that "workers (administrators-teachers) accept the organizational changes required for distance education" in second place with an arithmetic average (2.06) and a medium degree, and then paragraph No. (6) which states "The school has a degree of autonomy to deal with urgent problems Quickly" ranked third with an arithmetic average (2.02) and a medium degree, and ranked last Paragraph No. (3) which states that "the school ( the educational administration affiliated with the school) holds partnership and cooperation agreements with communications and information technology companies "with an average of (1.63) and a medium degree. We also note that the general average for the paragraphs of the axis is (1.95) and a standard deviation (0.539). The opinions of the respondents for this axis varied between a weak and moderate degree of practice.

\subsection{Results of the Third Question}

What are the obstacles to developing distance education programs in border schools from the Kingdom of Saudi Arabia?

To answer this question, arithmetic averages and standard deviations were extracted for all paragraphs of obstacles to developing distance education programs in border schools from the Kingdom of Saudi Arabia. 


\subsubsection{The Fifth Axis-Interface Design (Usability)}

Regarding the degree of importance: The arithmetic averages for the sections of the "Interface Design" axis ranged between (2.15-2.40), the most prominent of which was for paragraphs No. (3) and (7) which state: "It is easy for the learner to move within the site easily and quickly" and "The pages are simple and not crowded. With information "with a medium degree, then paragraph No. (8) came with an arithmetic mean (2.37) and a degree and a standard deviation (0.781), which states:" The site provides the feature of using multiple windows. "The lowest arithmetic averages came to Paragraph No. (9) which states: Screen elements in the logical design, with an arithmetic mean of (2.15) with a medium degree and a standard deviation of $(0.833)$. The general average for the paragraphs of the axis was (2.30) and a standard deviation (0.601). The opinions of the respondents in this axis were of a high degree of importance.

Relative to the degree of practice: The general arithmetic mean of the terms of the "interface design" axis was (1.97) and a standard deviation (0.621). The opinions of the respondents on this axis varied between a weak and moderate degree of practice. The arithmetic averages of the degree of practicing the axis of "interface design" ranged between (1.87-2.16), the highest of which was phrase No. (7) "pages are characterized by simplicity and not cluttered with information" with an arithmetic average of (2.16) and a standard deviation (0.760) with a medium degree, followed by statement No. (8) "The site provides the feature of using multiple windows" with an arithmetic average of (2.02) and a standard deviation (0.815) with a medium degree, and the phrase No. (4) "search engines are available on the site" with an arithmetic average of (1.87) and a standard deviation (0.797).

\subsubsection{The Sixth Axis - Evaluation}

Regarding the degree of importance: The arithmetic averages of the "evaluation" axis items ranged between (2.27 - 2.47) and the highest was for paragraph (8) which states that "the evaluation shall be carried out at appropriate times" with an arithmetic mean (2.47) and with a high degree, followed by paragraph No. (3) which states The evaluation system is a comprehensive system that includes all individuals within the school (students, teachers, and employees) in second place with an arithmetic average (2.45) and a high degree, then Paragraph No. (4) which states: "The evaluation system includes multiple aspects of performance and is not limited to one aspect of Aspects of performance "ranked third with an arithmetic average (2.38) and a high degree, and ranked last paragraph No. (7) which states:" The school has a specialized department to supervise and follow up the evaluation system "with an arithmetic average (2.27) and a medium degree, and the arithmetic average for the axis" evaluation " (2.35) with a medium degree. The arithmetic mean of the axis reached (2.35), and the opinions of the respondents on this axis were of a high degree of importance.

Relative to the degree of practice: The arithmetic averages of the paragraphs that measure the degree of practice of the "evaluation" axis ranged between (2.02 - 2.34), the most prominent of which was paragraph (3), which states: "The evaluation system is a comprehensive system that includes all individuals within the school (students, teachers, workers)" with an average Arithmetic (2.34) and a standard deviation (0.767), then paragraph No. (4) came with an arithmetic mean (2.23) with a medium degree and states that "the evaluation system includes multiple aspects of performance and is not limited to one aspect of performance." The lowest arithmetic averages came in Paragraph No. (1) which states that "students are evaluated through the electronic management system" with an arithmetic average of (2.02) with a medium degree. The general average for the paragraphs of the axis was (2.12) and a standard deviation (0.633). The opinions of the respondents varied between a medium and high degree of practice.

\section{Research Conclusions}

A. The reality of female teachers 'practice on distance learning programs in border schools in the Kingdom of Saudi Arabia is average, as these schools face a lack of specialists to provide technical and technical support for distance education and the lack of a specialized human resource management department with appropriate expertise to use communication and information technology means, in addition to Not having enough outside assistants and designers such as content design experts and programmers.

B. The ability to communicate effectively and identify the training needs of workers is one of the most important necessities for implementing distance learning programs, which are lacking in border schools in the Kingdom of Saudi Arabia.

C. The existence of a strategic plan to train workers on the required skills (now and in the future) for distance education, in addition to the existence of self-development orientations in the field of distance education, is one of the most important means of self-development for education that border schools lack in the Kingdom of Saudi Arabia. Also, schools do not use some national or foreign experts to train and develop workers. 
D. The use of technology is one of the most important requirements for developing remote education programs in border schools from the Kingdom of Saudi Arabia, as these schools lack an acceptance by workers for technology innovations, and there is support from the (upper-middle) administrative levels to use technological methods in performing daily tasks. In addition to the existence of interactive systems that encourage communication between students and support collaborative teamwork from a distance.

E. Supporting the administrative levels (upper-middle) is the changes required by the distance education system, and the school's failure to establish partnership and cooperation agreements with information and communication technology companies is one of the most prominent requirements for developing distance learning programs.

F. There are many obstacles that stand in the way of implementing distance learning programs in border schools from the Kingdom of Saudi Arabia, the most prominent of which is related to designing the interface of these programs, represented in: Their design does not facilitate the learner to move within the site easily and quickly, the pages are not simple and cluttered with information.

G. There are many obstacles that stand in the way of implementing distance learning programs in border schools from the Kingdom of Saudi Arabia, the most prominent of which is related to evaluation, as the evaluation system is not considered a comprehensive system that includes all individuals within the school (students, teachers, and workers). Evaluation on the multiple aspects of performance and is limited to one aspect of performance. Electronic tests are not subject to continuous review, and they are not at appropriate times.

\section{A Suggested Proposal}

\subsection{Define Vision}

Achieving leadership in diversifying and developing teaching and learning methods through the distance education system, based on employing modern information and communication technology, and for educational departments to be pioneers in spreading and facilitating education according to the latest methods based on educational technologies.

\subsection{Define Mission}

Equipping schools with all technological equipment and effective communication lines, supporting students with modern devices and teachers with modern training, and providing effective educational environments to achieve the goals of distance education in an era in which disasters and crises are frequent.

\subsection{The Suggested Proposal Axes}

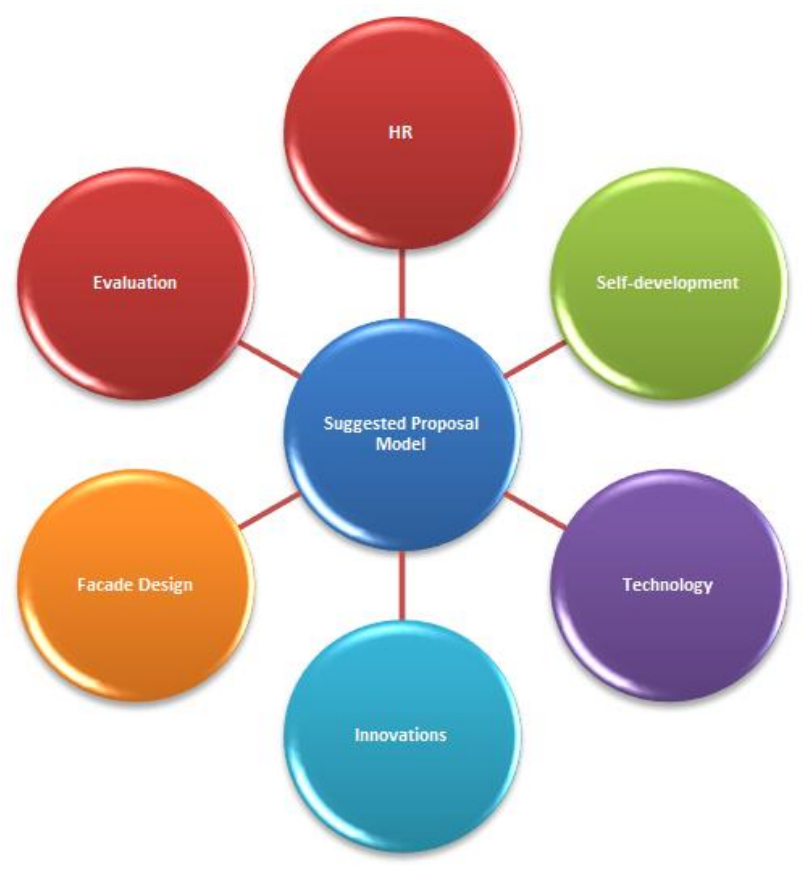

Figure 1. The axes of the suggested proposal 


\subsection{The Suggested Proposal Stages}

We can clarify the suggested proposal stages to Develop Distance Learning Programs in Border Schools in Saudi Arabia as follows:

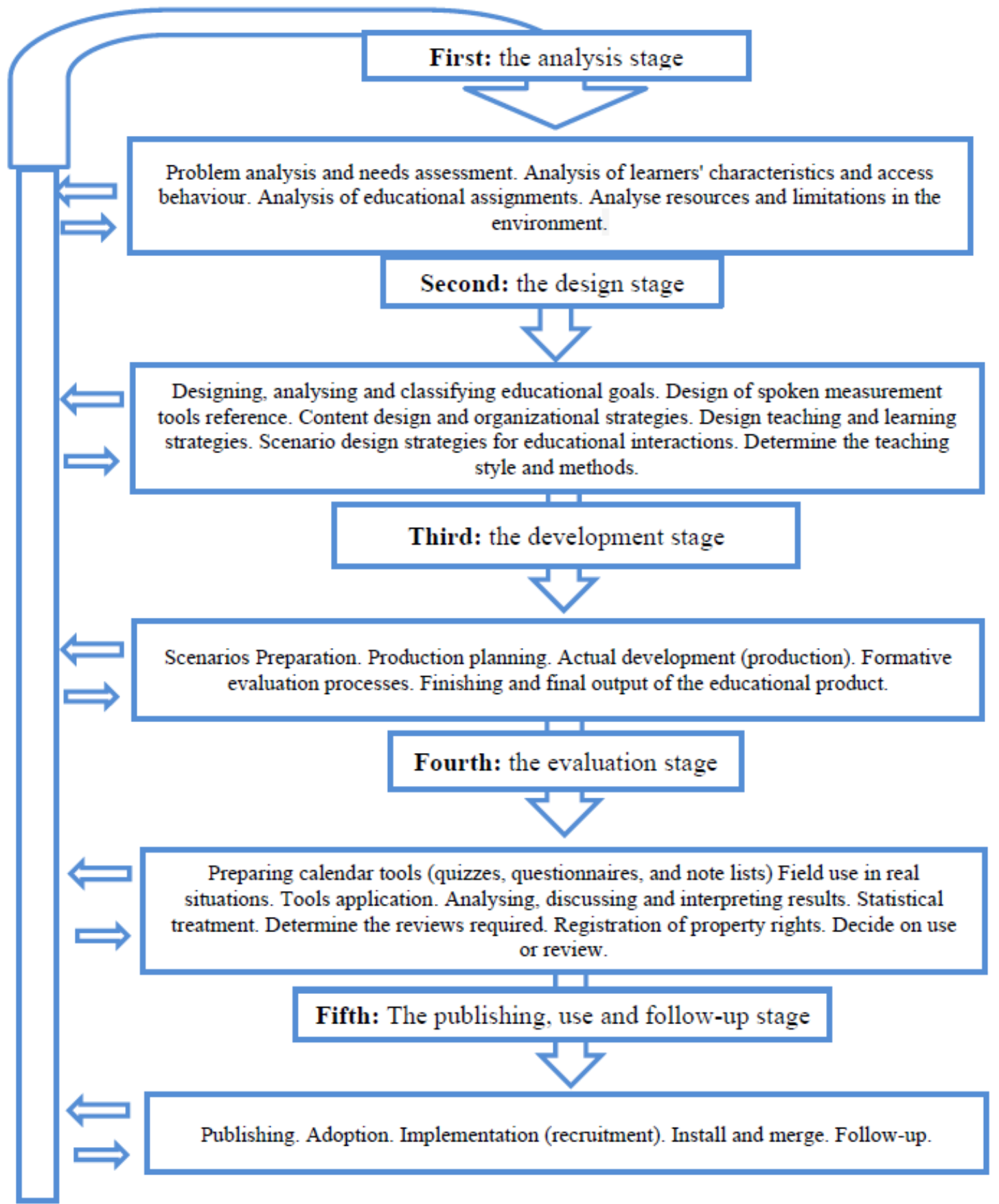

Figure 2. A suggested proposal stages

\section{Research Recommendations}

In light of the research results, we present some recommendations that could help improve the application of distance learning programs in border schools in the Kingdom of Saudi Arabia, as follows:

A. Providing border schools in the Kingdom of Saudi Arabia with human resources that have experience in using technology and seeking the help of some experts to train teachers. 
B. Creating interactive systems to increase the use of technology in border schools in the Kingdom of Saudi Arabia, in addition to working to encourage teachers to accept the use of technology in various educational processes.

C. Increasing the interaction of border schools in the Kingdom of Saudi Arabia and its cooperation with various information and communication technology companies to support them.

D. Improving the interfaces of distance learning programs by making them more interactive and easy.

E. Promote the building of a comprehensive evaluation system that includes all individuals in border schools in the Kingdom of Saudi Arabia, and it is treated from time to time as one of the means of distance education.

F. Spreading the culture of distance education in schools in the Kingdom of Saudi Arabia.

G. Reconsidering the remote training programs in border schools in the Kingdom of Saudi Arabia.

\section{Search Suggestions}

A. Study the design of a strategic plan for integrated schools based on distance education in the southern borders of the Kingdom of Saudi Arabia.

B. Studying the reality of distance education in the southern borders of the Kingdom of Saudi Arabia and finding out about its problems.

C. Studying the design of a training program for teachers of the southern border of schools in the Kingdom of Saudi Arabia on e-learning and distance education.

D. Study the effectiveness of distance education in southern border schools in the Kingdom of Saudi Arabia.

\section{References}

Alam, A., \& Tiwari, P. (2020). Putting the 'learning' back in remote learning, Policies to uphold effective continuity of learning through COVID-19. Office of Global Insight and Policy, UNICEF.

Al-Assaf, S. H. (2005). Introduction to Research in Behavioral Sciences. Al-Obeikan, Riyadh, Kingdom of Saudi Arabia.

Al-Awada, T. H. F. (2012). Difficulties in employing e-learning in Palestinian universities in Gaza as seen by teachers and students, Master's thesis. Al-Azhar University - Gaza, Palestine.

Al-Dabbasi, S. M. (2002). Globalization and Education. Riyadh, As-Safir Press.

Alghamdi, R. (2016). Towards Flexible Learning for Adult Learners in Saudi Higher Education. International Journal of Humanities and Social Science, 6(11), 24-30.

Ali, W. (2020). Online and Remote Learning in Higher Education Institutes: A Necessity in light of COVID-19 Pandemic. Higher Education Studies, 10(3), 16-25. https://doi.org/10.5539/hes.v10n3p16

Al-Kordali, Y. (2015). "Education” launches 12 educational satellite channels ... including two for students of the southern border. Al-Hayat newspaper. Retrieved from http://www.alhayat.com/Articles/10659631

Al-Makhdoub, R. A. (2008). Evaluation of the Experience of the Arab Open University in Designing a Distance Learning Program in Riyadh. College of Education, King Saud University, Saudi Arabia.

Al-Thumairi, A. (2015). "Twinning schools" is one of the "education" options for starting studies at the southern border. Electronic Economic Newspaper. Retrieved from http://www.aleqt.com/2015/08/05/article_979178.html

Amer, T., \& Al-Mousawi, A. S. (2010). Standards of Ethical Patterns for Computer and Internet Use by Faculty Members in Arab Higher Education Institutions. College of Education, Sultan Qaboos University, Oman.

Berrocoso, J. V., Arroyo, M. C. G., Videla. C. B., \& Cevallos, M. B. M. (2020). Trends in Educational Research about e-Learning: A Systematic Literature Review (2009-2018). Sustainability Journal, 12(12), 1-23. https://doi.org/10.3390/su12125153

Chu, H.-C. (2020). Supporting E-Learning with Emotion Regulation for Students with Autism Spectrum Disorder. Educational Technology \& Society, 23(4), 124-146.

Cubukcu, C., \& Akturk, C. (2020). The Rise of Distance Education during Covid-19 Pandemic and the Related Data Threats: A Study about Zoom. Paper was presented as abstract paper at Online International Conference on Covid-19 on 12-14 June 2020.

Drum, A. M. H. (2011). Activating E-Learning in General Secondary Education in the Kingdom of Saudi Arabia in Light of the Objectives of Islamic Education. Umm Al-Qura University, Kingdom of Saudi Arabia.

Guan, C., Ding, D., \& Ho, W. K. (2015). E-Learning in Higher Education for Adult Learners in Singapore. 
International Journal of Information and Education Technology, 5(5), 348-353. https://doi.org/10.7763/IJIET.2015.V5.528

Haful, A. (2015). Al-Dakhil for Students of the Southern Frontier: Alternatives Facilitate Education, Sabq Electronic Newspaper. Virtual classes, channels, portfolios, and interactive courses. Retrieved from https://sabq.org/S7gcTw

Haful, A. (2015). Al-Dakhil for Students of the Southern Frontier: Alternatives Facilitate Education. Virtual classes, channels, portfolios, and interactive courses, Sabq electronic newspaper. Retrieved from Https://sabq.org/S7gcTw.

Kanwar, A. (2020). Guidelines on Distance Education during COVID-19. Commonwealth of Learning, Burnaby, British Columbia, Canada.

Leontyeva, I. A. (2018). Modern Distance Learning Technologies in Higher Education: Introduction Problems. EURASIA Journal of Mathematics Science and Technology Education, 14(10), 1-8. https://doi.org/10.29333/ejmste/92284

Ministry of Higher Education. (2006). The Optimal System for E-Learning and Distance Education for Higher Education in the Kingdom of Saudi Arabia. Riyadh, Ministry Agency for Educational Affairs.

Monika, 亡. (2013). Analysis of Perceptions of Conventional and E-Learning Education in Corporate Training. Journal of Competitiveness, 5(4), 73-97. https://doi.org/10.7441/joc.2013.04.05

Salyers, V., Carter, L., Cairns, S., \& Durrer, L. (2014). The Use of Scaffolding and Interactive Learning Strategies in Online Courses for Working Nurses: Implications for Adult and Online Education. Canadian Journal of University Continuing Education, 40(1), 1-19. https://doi.org/10.21225/D59S3Z

Saykili, A. (2018). Distance education: Definitions, generations, key concepts and future directions. International Journal of Contemporary Educational Research, 5(1), 2-17.

\section{Copyrights}

Copyright for this article is retained by the author(s), with first publication rights granted to the journal.

This is an open-access article distributed under the terms and conditions of the Creative Commons Attribution license (http://creativecommons.org/licenses/by/4.0/). 